\title{
NOTES
}

\section{Stereo-Recognition of Propagating Chain End in the Cross-Dehydrocoupling Polym- erization of meso-1,3-Dimethyl-1,3-diphenyldisiloxanediol with Methylphenylsilane}

\author{
Motoi OISHI, Jeong-Yeol Moon, ${ }^{\dagger}$ Eiji SHIRAKAwa, and Yusuke KaWAKAMI ${ }^{\dagger}{ }^{\dagger}$ \\ Graduate School of Materials Science, \\ Japan Advanced Institute of Science and Technology [JAIST], \\ 1-1 Asahidai, Tatsunokuchi, Ishikawa 923-1292, Japan
}

(Received July 5, 2000; Accepted August 16, 2000)

KEY WORDS 1,3-Dimethyl-1,3-diphenyldisiloxanediol / Methylphenylsilane / Poly(methylphenylsi-
loxane)/ Cross-Dehydrocoupling Polymerization / Stereo-Recognition / Propagating Chain End /

There are two main strategies for the synthesis of stereoregular polymers. One is the stereospecific or -selective polymerization reactions of prochiral or racemic monomers. The other is the polymerization of optically active monomers which proceeds with complete retention or inversion of configuration of chiral centers. By using the latter strategy, we recently reported the synthesis of stereoregular and/or optically active poly(carbosilane), ${ }^{1}$ poly(carbosiloxane), ${ }^{2}$ and poly(siloxane), ${ }^{3}$ which are the first examples of stereoregular and/or optically active silicon-containing polymers.

Stereospecific or -selective polymerization reactions of prochiral or racemic organosilicon monomers have been insufficiently studied probably due to the lack of efficient asymmetric reactions for prochiral or racemic silicon compounds. Although several attempts on the synthesis of stereoregular poly(silane), ${ }^{4}$ poly(carbosiloxane) ${ }^{5}$ poly(sily ether), ${ }^{6}$ and poly(siloxane $)^{7}$ by ring-opening polymerization of cyclic organosilicon compounds ${ }^{4 c, 5,7}$ and transition metal catalyzed dehydrogenative polycondensation of prochiral hydrosilane compounds ${ }^{4 a, b, 6}$ have been reported, many of them failed to obtain highly stereoregular polymer. To synthesize highly stereoregular silicon-containing polymer, it is important to clarify the nature of the stereo-recognition of propagating chain end in the course of polymerization.

We have recently shown that cross-dehydrocoupling reaction of $\mathrm{Si}^{*} \mathrm{H}$ and $\mathrm{Si}^{*} \mathrm{OH}$ in the presence of rhodium catalyst proceeds with retention of configuration at both silicon chiral centers. ${ }^{3 a}$ Since, 1,3-dimethyl-1,3-diphenyldisiloxanediol $\mathbf{1}^{8}$ consisting of stereoisomers of various compositions can be easily prepared, our interest is focused on the stereo-recognition of propagating chain end in the cross-dehydrocoupling polymerization of $\mathbf{1}$ with prochiral methylphenylsilane $\mathbf{2}$.

\section{EXPERIMENTAL}

A typical polymerization procedure is as follows. A solution of meso-1 (100\% pure) $(0.291 \mathrm{~g}, 1.0 \mathrm{mmol}), 2$ $(0.122 \mathrm{~g}, 1.0 \mathrm{~mol})$ and triethylamine $(0.051 \mathrm{~g}, 0.5 \mathrm{mmol})$ was added to $\mathrm{RhCl}\left(\mathrm{PPh}_{3}\right)_{3}(0.009 \mathrm{~g}, 1.0 \mathrm{~mol} \%)$, and re- acted at $60^{\circ} \mathrm{C}$ for $12 \mathrm{~h}$ under nitrogen atmosphere. The reaction mixture was filtered on silica gel to remove the catalyst. Removal of the volatile materials afforded a crude polymer. After reprecipitation from $\mathrm{Et}_{2} \mathrm{O}$ into methanol, the polymer was collected and dried in vacuo $(0.191 \mathrm{~g}, 47 \%$ yield $)$. The polymer was identified as poly(methylphenylsiloxane) (PMPS) by ${ }^{1} \mathrm{H},{ }^{13} \mathrm{C}$, and ${ }^{29} \mathrm{Si}$ nuclear magnetic resonance (NMR). GPC $M_{\mathrm{n}}=14000, M_{\mathrm{w}} /$ $M_{\mathrm{n}}=1.9 ;{ }^{1} \mathrm{H} \mathrm{NMR}\left(500 \mathrm{MHz}, \mathrm{CDCl}_{3}\right) \delta 0.04,0.09$, and 0.14 (three singlets, $3 \mathrm{H}, \mathrm{CH}_{3}$, corresponding to $I, H$, and $S$, respectively) ${ }^{3 \mathrm{a}}, 7.01-7.18$ (br, $2 \mathrm{H}$, phenyl protons), $7.18-7.56$ (br, $3 \mathrm{H}$, phenyl protons); ${ }^{13} \mathrm{C} \mathrm{NMR}(125 \mathrm{MHz}$, $\left.\mathrm{CDCl}_{3}\right) \delta-0.47(I),-0.38(H)$, and $-0.29(S)^{3 \mathrm{a}}$ (methyl carbons), $127.43(S), 127.49(H)$, and $127.53(I)$ (metaphenyl carbons), 127.9 (para-phenyl carbon), 133.3 (ortho-phenyl carbon), $136.7(S), 136.9(H), 137.1(I)$ (ipso-phenyl carbons); ${ }^{29} \mathrm{Si} \mathrm{NMR}\left(99 \mathrm{MHz}, \mathrm{CDCl}_{3}\right) \delta-$ 33.8 (singlet); IR (neat, $\mathrm{cm}^{-1}$ ) 3071, 3050, 3025, 3004, 2962, 2903, 1592, 1429, 1261, 1125, and 1020.

\section{RESULTS AND DISCUSSION}

Cross-dehydrocoupling polymerization reactions of $\mathbf{1}$ consisting of different stereoisomers (meso/dl-1; $(S, S)$ : $(S, R):(R, R)=25: 50: 25, d l$ rich $1 ;(S, S):(S, R):(R$, $R)=35: 30: 35$, and meso; $100 \%$ pure) with 2 were carried out in bulk at $60^{\circ} \mathrm{C}$ for $12 \mathrm{~h}$. The results are summarized in Table I. Triad tacticity of the resulting PMPS's was evaluated by the integral ratio of ipso-carbon peaks in ${ }^{13} \mathrm{C} \mathrm{NMR}{ }^{3 \mathrm{a}}$ Calculated triad tacticity was obtained assuming no stereoselection by propagating chain end in the polymerization.

The polymerization of meso-1 gave PMPS's rich in syndiotactic triad $(r r=18-20 \%)$ compared with calculated value $(r r=8 \%$ ) (entries 5 and 6 ) when catalyzed by $\mathrm{RhCl}$ $\left(\mathrm{PPh}_{3}\right)_{3}$. Contrary to the fact that triad tacticity was almost identical to the calculated value in the polymerization of meso/dl-1 and $d l$ rich 1 (entries 1-4). This is an interesting fact indicating that the polymerization of 1 with 2 proceeded with stereo-recognition by propagating chain end for meso-1, and without stereo-recognition when meso content in the monomer is less than $50 \%$.

\footnotetext{
${ }^{\dagger}$ On leave from Pusan National University, Korea as a postdoctoral scientist supported by JAIST.

${ }^{+\dagger}$ To whom correspondence should be addressed.
} 
Table I. Cross-dehydrocoupling Polymerization of $\mathbf{1}$ with 2

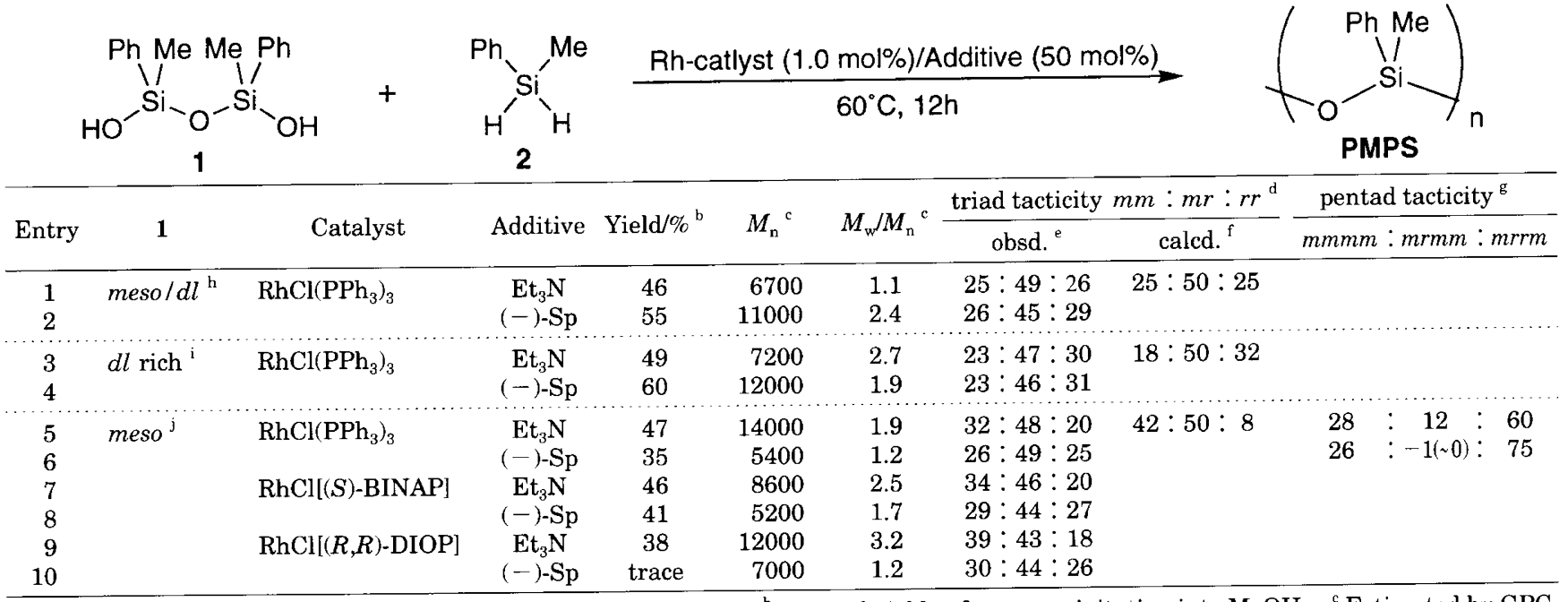

${ }^{a}$ The polymerization reactions were carried out at $60^{\circ} \mathrm{C}$ for $12 \mathrm{~h} .{ }^{\mathrm{b}}$ Isolated yields after reprecipitation into $\mathrm{MeOH}$. ${ }^{\mathrm{c}}$ Estimated by GPC with polystyrene standard (THF as an eluent). ${ }^{d}$ Determined by ${ }^{13} \mathrm{C}$ NMR at ipso carbon. ${ }^{\mathrm{e}}$ The error is about $\pm 1 \%$. ${ }^{\mathrm{f}} \mathrm{Calculated}$ triad tacticity was obatined assuming no stereoselection by propagating chain end. ${ }^{\mathrm{g}}$ Calculated from traid tacticity. ${ }^{\mathrm{h}}(\mathrm{S}, \mathrm{S}):(\mathrm{S}, \mathrm{R}):(\mathrm{R}, \mathrm{R})=$ $25: 50: 25 .{ }^{\mathrm{i}}(\mathrm{S}, \mathrm{S}):(\mathrm{S}, \mathrm{R}):(\mathrm{R}, \mathrm{R})=35: 30: 35 .{ }^{\mathrm{J}} 100 \%$ pure.

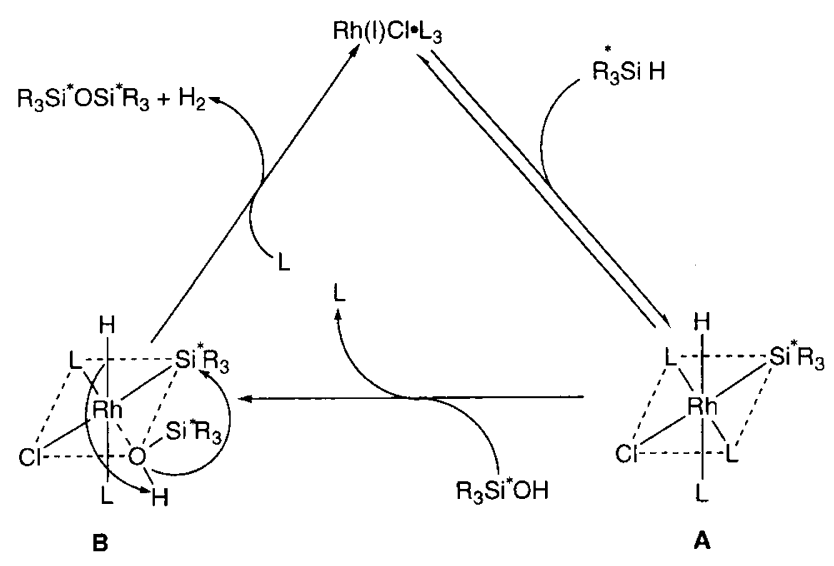

Figure 1. Tentative reaction mechanism of Rh-catalyzed crossdehydrocoupling reaction of $\mathrm{R}_{3} \mathrm{Si}^{*} \mathrm{H}$ with $\mathrm{R}_{3} \mathrm{Si}^{*} \mathrm{OH}$.

Stress will be put on this point in the discussion.

Polymerization reactions with optically active Rhcatalysts such as $\operatorname{RhCl}[(S)$-BINAP $]$ and $\operatorname{RhCl}[(R, R)$ DIOP] gave PMPS's with triad tacticity $[r r=20 \%$ (entry 7), and $r r=18 \%$ (entry 9)] similar to that of PMPS catalyzed by $\mathrm{RhCl}\left(\mathrm{PPh}_{3}\right)_{3}$ (entry 5 ), suggesting no effect of the optically active Rh-catalyst on stereo-recognition of propagating chain end. Use of $(-)$-spartein $((-) \mathrm{Sp})$ instead of triethylamine $\left(\mathrm{Et}_{3} \mathrm{~N}\right)$ as the additive showed somewhat higher syndiotactic triad $(r r=26-27 \%$, entries 6,8, and 10).

Tentative reaction mechanism for $\mathrm{Rh}$-catalyzed crossdehydrocoupling reaction of $\mathrm{R}_{3} \mathrm{Si}^{*} \mathrm{H}$ with $\mathrm{R}_{3} \mathrm{Si}^{*} \mathrm{OH}$ in the presence of an amine is proposed in Figure 1 considering the generally accepted Wilkinson catalyst reaction mechanism. The mechanism involves the oxidative addition of $\mathrm{Si}^{*} \mathrm{H}$ to $\mathrm{Rh}$ (I) to form $\mathrm{Rh}$ (III) intermediate $\mathbf{A}$, followed by the coordination of $\mathrm{Si}^{*} \mathrm{OH}$ to give intermediate $\mathbf{B}$. Attack of $\mathrm{Rh}-\mathrm{H}$ bond on silanol hydrogen gives hydrogen molecules, and following reductive elimination gives $\mathrm{R}_{3} \mathrm{Si}^{*} \mathrm{OSi}^{*} \mathrm{R}_{3}$. It was reported that configuration of silicon atom of $\mathrm{Si}^{*} \mathrm{OH}$ is completely retained, and there is some racemization of $\mathrm{Si}^{*} \mathrm{H}$ chiral center depending on the reaction conditions, although the stereochemistry of $\mathrm{Si}^{*} \mathrm{H}$ in oxidative addition is basically retention of configuration. ${ }^{3 a}$ Tilley proposed a two step $\sigma$-bond methathesis reaction mechanism for the condensation of two $\mathrm{PhSiH}_{3}$ molecules catalyzed by zirconocene or hafnocene with evolution of hydrogen gas. ${ }^{9}$

Figure 2 illustrates the possible stereo-sequence formation in the polymerization to give PMPS. The configuration of $\mathrm{SiH}$ terminal is determined in the reaction with $\mathrm{Si}^{*} \mathrm{OH}$ terminal to give $m m$ or $m r$ triad $\mathrm{Si}^{*} \mathrm{H}$ terminal. Since prochiral silicon atom of $\mathbf{2}$ is attacked twice by two chiral $\mathrm{Si}^{*} \mathrm{OH}$ terminals when being incorporated into the polymer chain, stereochemistry of silicon atom derived from 2 is affected twice by the reaction with two $\mathrm{Si}^{*} \mathrm{OH}$ of propagating chain end from 1 to give five consecutive silicon chiral centers. Accordingly, stereoregularity of PMPS obtained from meso-1 and $\mathbf{2}$ should be discussed based on the pentad tacticity.

Population in percentage of possible pentad sequences $\mathrm{mmmm}, \mathrm{mrmm}$, and $\mathrm{mrrm}$ were estimated from the data of triad tacticity for entries 5 and 6 in Table I. When $x, y$, and $z$ are defined as the population of $\mathrm{mmmm}, \mathrm{mrmm}$, and $\mathrm{mrrm}$, respectively, the population of isotactic triad $(\mathrm{mm})$, heterotactic triad $(\mathrm{mr})$, and syndiotactic triad $(r r)$ can be calculated by $[m m]=x+y / 3$, $[m r]=2 y / 3+2 z / 3$, and $[r r]=z / 3$. Only $m r r m$ pentad among the possible three pentad sequences can afford the syndiotactic triad $r r$. For the polymer obtained in the presence of $\mathrm{Et}_{3} \mathrm{~N}$ (Table I, entry 5, $m m: m r: r r=32$ : $48: 20$ ), the population of $m r r m$ pentad, namely, $z$, is calculated as $60 \%$ by using the equation of $[r r]=20 \%=z$ l 3 . The population of $m m r m, y$, is calculated as $12 \%$ from $z=60 \%$ and $[m r]=48 \%=2 y / 3+2 z / 3$. As a result, the population of $\mathrm{mmmm}$ pentad, $x$, is calculated as $28 \%$.

Similarly, the population of pentad tacticity for entry 6 in Table I $(\mathrm{mm}: m r: r r=26: 49: 25)$ was calculated as $m m m m=26, m r m m=-1(\sim 0)$, and $m r r m=75 \%$ in the presence of $(-)$-Sp.

Since the concentration of $\mathrm{mrrm}$ pentad is higher than 


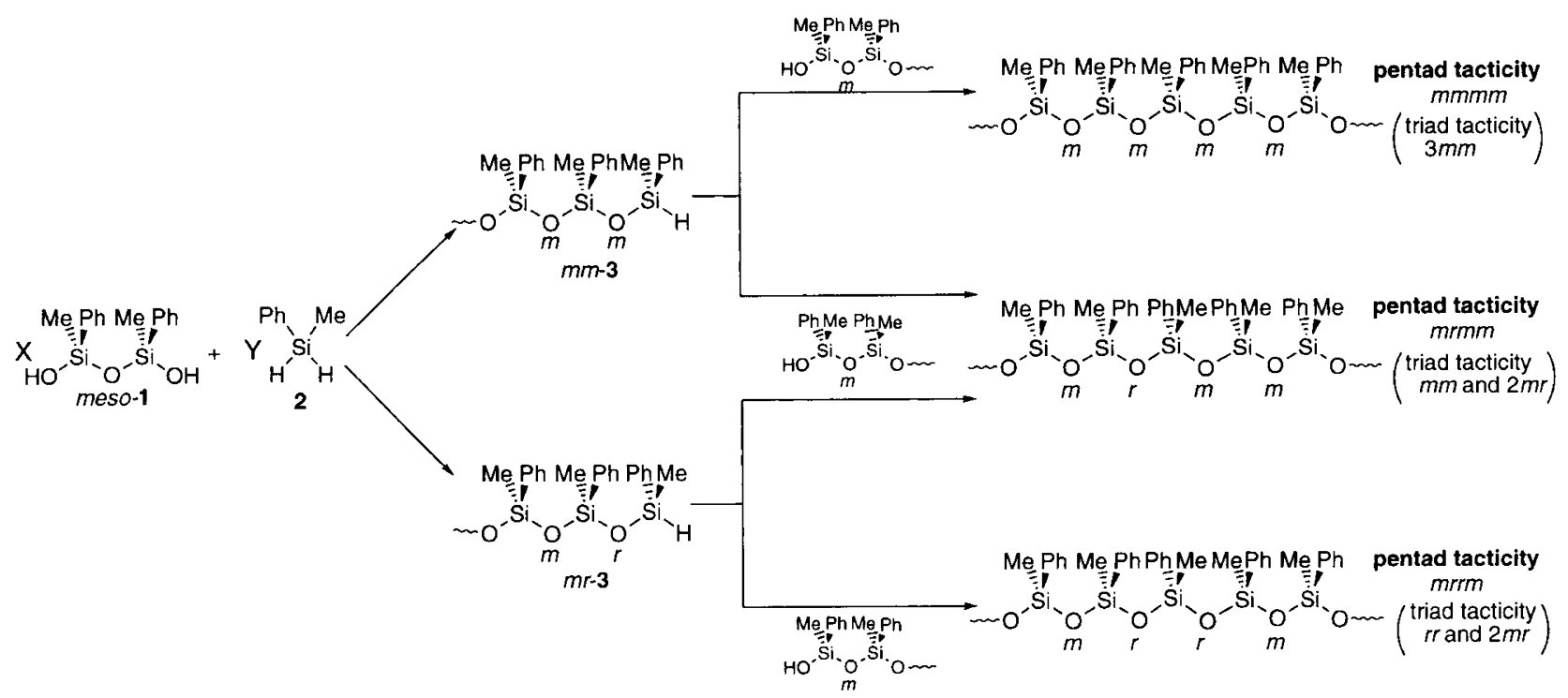

Figure 2. Possible stereo-sequences of PMPS in the polymerization of meso-1 with 2.

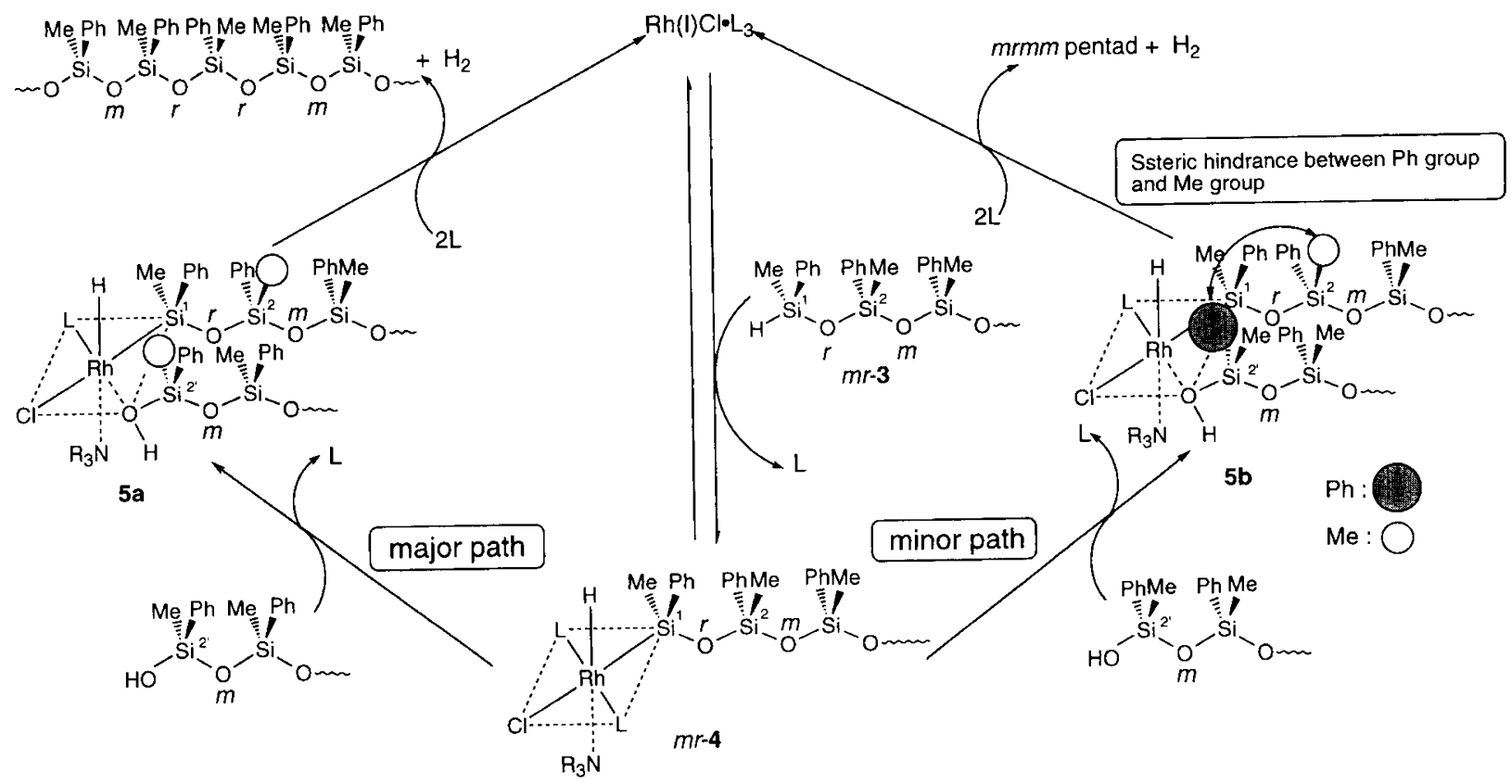

Figure 3. Plausible mechanism of stereo-recognition of propagating chain end in polymerization of meso-1 with 2.

the calculated one, $m r$ triad $\mathrm{Si}^{*} \mathrm{H}(m r-3)$ terminal seems to be preferentially formed as the propagating chain end in the initial coupling of 2 with $\mathrm{Si}^{*} \mathrm{OH}$ terminal as shown in Figure 2. Coupling between this $m r-3$ terminal and $\mathrm{Si}^{*} \mathrm{OH}$ terminal with same configuration gives $m r r m$ pentad as the major stereo-sequence. The $\mathrm{mmmm}$ pentad is formed by the coupling of $m m$ triad $\mathrm{Si}^{*} \mathrm{H}(\mathrm{mm}$ 3) terminal, as the minor chain end, with $\mathrm{Si}^{*} \mathrm{OH}$ terminal with opposite configuration. Coupling between $\mathrm{mm}$ or $m r$ triad $\mathrm{Si}^{*} \mathrm{H}$ and $\mathrm{Si}^{*} \mathrm{OH}$ with same or opposite configuration gives $\mathrm{mrmm}$ pentad in low concentration in the presence of $\mathrm{Et}_{3} \mathrm{~N}$.

Stereo-recognition of propagating chain end in the polymerization of meso-1 with 2 is interpreted based on the reaction mechanism proposed in Figure 1 (Figure 3). The oxidative addition of preferentially formed $m r$ triad $\mathrm{Si}^{*}$
$\mathrm{H}$ chain end, $m r-3$, affords intermediate $m r-4$, to which $\mathrm{Si}^{*} \mathrm{OH}$ chain end with same configuration with $\mathrm{Si}^{*} \mathrm{H}$ terminal of $m r-3$ preferentially coordinates to give intermediate $\mathbf{5 a}$. Formation of $\mathbf{5 a}$ may be favored by the absence of steric hindrance between substituents on the $\mathrm{Si}^{1}$ or $\mathrm{Si}^{2}$ and $\mathrm{Si}^{2}$ atoms in the polymer chain in the coordination step, alternatively, the reductive elimination from $5 \mathbf{a}$ may be favored to produce $\mathrm{mrrm}$ pentad. Coordination of $\mathrm{Si}^{*} \mathrm{OH}$ chain end with opposite configuration to $m r-3$ seems less favorable because of the steric interaction resulting in the formation of $\mathrm{mrmm}$ pentad as the minor sequence.

Reaction of $m m-4$ with $\mathrm{Si}^{*} \mathrm{OH}$ with opposite configuration to that of $\mathrm{Si}^{*} \mathrm{H}$ of $m m-3$ seems favored to produce $\mathrm{mmmm}$ pentad over $\mathrm{mrmm}$ pentad, which is produced by the reaction of $m m-3$ with $\mathrm{Si}^{*} \mathrm{OH}$ with same configu- 
ration.

In other words, $\mathrm{Si}^{*} \mathrm{H}$ propagating chain end preferentially reacts with $\mathrm{Si}^{2} \mathrm{OH}$ chain end with opposite configuration of the penultimate $\mathrm{Si}^{2}$ of $m r-3$ or $m m-3$ to produce $\mathrm{mrrm}$ or $\mathrm{mmmm}$ pentad over $\mathrm{mrmm}$ pentad regardless of whether the $\mathrm{SiH}$ chain end is $(S)$ - or $(R)$ configuration. Thus, existence of $m$ diad derived from meso-1 seems the most important factor for the stereorecognition in the polymerization. On the contrary, $r$ diad derived from $d l$-1 does not exhibit any stereorecognition resulting in triad tacticity in accordance with the calculated value.

The difference in stereo-selection between the reactions in the presence of $\mathrm{Et}_{3} \mathrm{~N}$ and (-)-Sp (entries 5 and 6 in Table I) may be due to the existence or non-existence of racemization of $\mathrm{Si}^{*} \mathrm{H}$ terminal of $m r-3$ or $m m-3$ in the reversible oxidative addition step to form $m r-4$ or $m$ 4. ${ }^{3 \mathrm{a}}$ The role of bulky (-)-Sp is considered to suppress the racemization of $m r-4$ or $m m-4$ by the existence at the apical position of rhodium center. The effect of the molecular weight of the polymer on stereo-recognition in the polymerization of meso-1 with 2 was considered not significant (entries 5-10 in Table I). Thus, polymerization of meso-1 with $\mathbf{2}$ was found to proceed with thpreferentially formation of $\mathrm{mrrm}$ pentad sequence.

In conclusion, we observed stereo-recognition by terminal disiloxane silanol with $m$ diad in Rh-catalyzed cross-dehydrocoupling polymerization of meso-1,3-dimethyl-1,3-diphenylsiloxanediol 1 with methylphenylsilane 2 in the presence of triethylamine or (-)-Sp. $75 \% \mathrm{mrrm}$ pentad of PMPS was obtained, when (-)-Sp was used as the additive. Further study on the synthesis of highly stereoregular poly(siloxane) by polymerization of prochiral or racemic silicon monomers is now in progress.

Acknowledgments. The authors are grateful to ShinEtsu Chemicals Co. Ltd. for generous donation of organosilicon compounds. This work was partially supported by a grant in aid for Scientific Research (11450354) from the Ministry of Education, Science,
Sports, and Culture, Japanese government.

\section{REFERENCES}

1. a) Y. Kawakami, K. Nakao, S. Shinke, and I. Imae, Macromolecules, 32, 6874 (1999). b) Y. Kawakami, T. Takahashi, Y. Yada, and I. Imae, Polym. J., 30, 1001 (1998). c) Y. Kawakami, K. Takeyama, O. Ooi, and K. Komuro, Macromolecules, 31, 551 (1998)

2. a) Y. Li and Y. Kawakami, Macromolecules, 32, 548 (1999). b) Y. Li and Y. Kawakami, Macromolecules, 31, 5592 (1998).

3. a) M. Oishi, J-Y. Moon, W. Janvikul, and Y. Kawakami, Polym. Int., in press. b) M. Oishi and Y. Kawakami, Macromolecules, 33, 1960 (2000).

4. For poly(phenylsilane) rich in syndiotacticity, see: a) N. Choi, S. Onozawa, T. Sakakura, and M. Tanaka, Organometallics, 16, 2765 (1997). b) J. P. Banovertz, K. M. Stein, and R. M. Waymouth, Organometallics, 10, 3430 (1991). For poly(methylphenylsilane) rich in heterotacticity, see: c) E. Fossum and K. Matyjaszewski, Macromolecules, 28, 1618 (1995).

5. Y. Li and Y. Kawakami, Macromolecules, 33, 1560 (2000).

6. Y. Li, M. Seino, and Y. Kawakami, Macromolecules, 33, 5311 (2000).

7. For poly(methylphenylsiloxane) rich in isotacticity, see: a) B. Momper, Th. Wanger, U. Maschke, M. Ballauff, and E. W. Fisher, Polym. Commun., 31, 186 (1990). b) S. J. Clarson, J. A. Semlyen, and K. Dodgson, Polym. Prepr., Am. Chem. Soc., Div. Polym. Chem., 31, 563 (1990). c) M. D. Curtis, S. Thanedar, and M. Ejshiek, Polym. Prepr., Am. Chem. Soc., Div. Polym. Chem., 25, 224 (1984). d) T. N. Baratova, V. P. Mileshkevich, and V. I. Gurari, Poly. Sci. USSR, 25, 2899 (1983). e) T. N. Baratova, V. P. Mileshkevich, and V. I. Gurari, Poly. Sci. USSR, 24, 27 (1982). f) L. S. Bresler, V. P. Mileshkevich, Yu. A. Yuzheleskii, and N. P. Timofeeva, $Z h$. Struct, Khim. SSSR, 19, 453 (1978). g) E. A. Bostik, Polym. Prepr., Am. Chem. Soc., Div. Polym. Chem., 10, 877 (1969). For poly[methyl(3,3,3-trifluoropropyl)siloxane] rich in isotacticity, see: h) K. P. Battjes, C -M. Kuo, R. L. Miller, and J. C. Saam, Macromolecules, 28, 790 (1995). i) C -M. Kuo, J. C. Saam and R. B. Taylor, Polym. Int., 33, 2663 (1994).

8. a) M. Oishi and Y. Kawakami, Org. Lett., 1, 549 (1999). b) A. W. P. Jarvie, A. Holt, J. Homer, and H. J. Hickton, J. Chem. Soc. Sect B, 978 (1969). c) W. H. Daudt and J. F. Hyde, J. Am. Chem. Soc., 74, 386 (1952).

9. T. D. Tilley, Acc. Chem. Res., 26, 22 (1993). 